\title{
THE BEST BOUNDS IN GAUTSCHI'S INEQUALITY
}

\author{
Neven Elezović, CARla Giordano AND Josip PEČARIĆ
}

\begin{abstract}
Different approach to both Gautschi's inequalities (1) and (2) is given. This results in obtaining the best upper bound in (1) and the best lower bound in (2). The main result is the proof of the convexity of the function $[\Gamma(x+t) / \Gamma(x+s)]^{1 /(t-s)}$ for $|t-s|<1$. Several new very simple inequalities for digamma function, like $\psi^{\prime}(x)<\exp (-\psi(x))$ or $\psi(x+1)<\log \left(x+e^{-\gamma}\right)$ are also proved.
\end{abstract}

Mathematics subject classification (1991): 33B15, 26D07.

Key words and phrases: Gauchi’s inequality, convex function, gamma functon, digamma function.

\section{REFERENCES}

[1] M. AbRamowitz, I. A. STEGUn (EDS), Handbook of Mathematical Functions, fourth printing, National Bureau of Standards, Washington, D.C., 1965.

[2] J. Bustoz, M. E. M. Ismail, On Gamma Function Inequalities, Math. Comp. 47 (1986), 659-667.

[3] N. ElezoviĆ, J. PEČARIĆ, Differential and integral $f$-means and applications to digamma function, Math. Inequal. Appl. 3 (2000), 189-196.

[4] W. GAUTSCHI, Some elementary inequalities relating to the Gamma and incomplete gamma function, J. Mathematics and Physics 38 (1959), 77-81.

[5] C. Giordano, A. LAFORgia AND J. PeČARIĆ, Supplements to known inequalities for some special functions, J. Math. Anal. Appl. 200 (1996), 34-41.

[6] C. GIORdANO, A. LAFORGIA AND J. PeČARIĆ, Unified treatment of Gautschi-Kershaw type inequalities for the gamma function, J. Comput. Appl. Math. 99 (1998), 166-175.

[7] C. Giordano, A. LAFORgIA AND J. PeČARIĆ, Monotonicity properties for some functions involving the ratio of two gamma functions, Funzioni speciali e applicazioni, eds. A. Bellacicco, A. Laforgia, FrancoAngeli publ., Milano, 1998, pp. 35-42.

[8] D. Kershaw, Some extensions of W. Gautschi's inequalities for the gamma functions, Math. of Computation 41, 164 (1983), 607-611.

[9] A. LAFORGIA, Further inequalities for the gamma function, Math. of Computation 42, 166 (1984), 597-600.

[10] I. B. LAZAREvić, A. LuPAŞ, Functional equations for Wallis and gamma functions, Publ. Elektrotehn. fak. Univ. Beograd, Serie Electronique, Telecommunications, Automatique No. 461-497 (1974), $245-251$.

[11] M. MERKLE, Convexity, Schur-conevxity and bounds for the gamma function involving the digamma function, Rocky Mountain J. of Math. 28 (1998), 1053-1066. 